Article

\title{
Graphene Oxide Nanoribbons Induce Autophagic Vacuoles in Neuroblastoma Cell Lines
}

\author{
Emanuela Mari ${ }^{1, *}$, Stefania Mardente ${ }^{1, *}$, Emanuela Morgante ${ }^{1}$, Marco Tafani ${ }^{1,3}$, \\ Emanuela Lococo ${ }^{1}$, Flavia Fico ${ }^{1}$, Federica Valentini ${ }^{2}$ and Alessandra Zicari ${ }^{1}$ \\ 1 Department of Experimental Medicine, University of Rome Sapienza, 00161 Roma, Italy; \\ emanuela.morgante@uniroma1.it (E.M.); marco.tafani@uniroma1.it (M.T.); emanuela.lococo@yahoo.it (E.L.); \\ flavia.fico@unifr.ch (F.F.); alessandra.zicari@uniroma1.it (A.Z.) \\ 2 Department of Chemistry, University of Rome Tor Vergata, 00173 Roma, Italy; \\ federicavalentini.chem@gmail.com \\ 3 Laboratory of Molecular and Cellular Pathology, IRCCS San Raffaele Pisana, 00163 Rome, Italy \\ * Correspondence: emanuela.mari@uniroma1.it (E.M.); Stefania.mardente@uniroma1.it (S.M.); \\ Tel.: +39-06-4997-0662 (E.M. \& S.M.)
}

Academic Editor: Anthony Lemarié

Received: 7 July 2016; Accepted: 23 November 2016; Published: 29 November 2016

\begin{abstract}
Since graphene nanoparticles are attracting increasing interest in relation to medical applications, it is important to understand their potential effects on humans. In the present study, we prepared graphene oxide (GO) nanoribbons by oxidative unzipping of single-wall carbon nanotubes (SWCNTs) and analyzed their toxicity in two human neuroblastoma cell lines. Neuroblastoma is the most common solid neoplasia in children. The hallmark of these tumors is the high number of different clinical variables, ranging from highly metastatic, rapid progression and resistance to therapy to spontaneous regression or change into benign ganglioneuromas. Patients with neuroblastoma are grouped into different risk groups that are characterized by different prognosis and different clinical behavior. Relapse and mortality in high risk patients is very high in spite of new advances in chemotherapy. Cell lines, obtained from neuroblastomas have different genotypic and phenotypic features. The cell lines SK-N-BE(2) and SH-SY5Y have different genetic mutations and tumorigenicity. Cells were exposed to low doses of GO for different times in order to investigate whether GO was a good vehicle for biological molecules delivering individualized therapy. Cytotoxicity in both cell lines was studied by measuring cellular oxidative stress (ROS), mitochondria membrane potential, expression of lysosomial proteins and cell growth. GO uptake and cytoplasmic distribution of particles were studied by Transmission Electron Microscopy (TEM) for up to $72 \mathrm{~h}$. The results show that GO at low concentrations increased ROS production and induced autophagy in both neuroblastoma cell lines within a few hours of exposure, events that, however, are not followed by growth arrest or death. For this reason, we suggest that the GO nanoparticle can be used for therapeutic delivery to the brain tissue with minimal effects on healthy cells.
\end{abstract}

Keywords: graphene oxide; nanoribbons; neuroblastoma; cytotoxicity; autophagy

\section{Introduction}

For cancer to be treated effectively, a drug has to be delivered selectively to the site of lesion and delivery to normal cells has to be minimized. A drug delivery system should have a simple and non-toxic design. Graphene is an allotrope of carbon that has attracted biological interest due to its favorable physicochemical properties [1]. In the case of tumors, a targeted drug delivery system is necessary in order to increase the therapeutic effect of drugs and to diminish cytotoxicity to adjacent cells. Polymeric carriers, micelles, dendrimers, liposomes, solid lipid carriers, gold carriers and carbon based carriers have been developed recently and reviewed in [2]. The size of nanoparticles, 
concentration and biodiversity of drugs that can be carried as well as the biodistribution within target tissues seems to influence the choice of the nanoparticle to be used for different targets.

Graphene oxide (GO) in particular, has attracted increasing attention because of its numerous hydrophilic groups, water solubility and high surface area-to-volume ratio, which ensures a relevant loading capacity of bioactive molecules that enables pharmacological applications [3]. The unique chemical properties of GO allow different chemical substances to be bound to the same GO particles. Furthermore, very low doses of GO need to be used in order to reduce cytotoxicity. The basic graphene structure has been functionalized in nanoribbons, nanosheets, and nanotubes and, in some cases, interfaced with other types of nanomaterials such as quantum dots. GO has also been shown to bind to a large number of molecules including proteins, DNA and polymers. Although nanotubes have been shown to be toxic for biological systems, recent studies have focused on the biosafety of GO nanoparticles in cells and live biosystems by looking at different aspects such as cell growth, viability, induction of apoptosis [4]. However, more studies focusing on GO nanoparticles' stability and their eventual metabolism in cells as well as their role in different aspects of cell biology are required.

Neuroblastoma is the most frequent solid tumor in childhood arising from precursors of the sympathetic nervous system that fail to differentiate. Clinical behavior in neuroblastomas is variable and goes from highly invasive and resistant to therapy with low survival and high mortality to spontaneous regression or change into benign ganglioneuromas [5]. The different clinical variables depend on the different mutations in oncogenes, oncosuppressor genes and factors that regulate them, such as miRs [6]. The highly metastatic and aggressive subtypes of neuroblastoma need new therapeutic approaches that aim to suppress malignant phenotypes and to induce differentiation of non tumorigenic elements. The two different cell lines reported in the present study show different tumorigenicity, the SK-N-BE(2) cell line is less differentiated and has MYC-N amplification. One possible therapeutic approach would be to enhance growth suppressor genes and to suppress growth of undifferentiated cells [7,8]. New immune therapies targeting infiltrating macrophages, which seem to promote tumor growth and resistance to therapy, are developed in neuroblastoma [9]. One problem that needs to be addressed is how to direct new molecules at intra-cellular targets. In a recent study [10], graphene nanocomposites were combined with antibodies, folic acid and miR222 for inducing apoptosis in liver cancer cells. More recently, Rezaei et al. [11] have used a graphene based gene carrier for DNA transfection into mammalian cells, with a low rate of cell death, even though the authors report a slight increase of cell death in AGS cells treated with $1 \mu \mathrm{g}$ of GO. Other authors [12] have found above $20 \%$ of cell death caused by $20 \mu \mathrm{g}$ of GO nanoparticles in glioblastoma cell lines and Lammel et al. [13] have shown that GO nanoplatelets exert cytotoxicity with plasma membrane damage and induction of oxidative stress at concentrations above $4 \mu \mathrm{g} / \mathrm{mL}$ in a human hepatocellular cell line (Hep G2).

The present study reports on uptake and biocompatibility of small diameter (22-26 nm) GO nanoribbons in two different neuroblastoma cell lines. We show that very small doses of GO are able to induce autophagy within the first $48 \mathrm{~h}$ of exposure, after this time cells recover and are able to grow.

\section{Results}

\subsection{Uptake of Graphene Oxide (GO) by SK-N-BE(2) and SH-SY5Y Cells}

Cells $\left(10^{5} / \mathrm{mL}\right)$ were treated with $2.0 \mu \mathrm{g} / \mathrm{mL}$ of GO at different times and uptake was analyzed with spectophotometer readings at $340 \mathrm{~nm}$. Higher concentrations of GO in both cell lines lead to an increasingly higher rate of necrosis. Figure S1 shows the rate of cell death in cells treated with different concentrations of $\mathrm{GO}$ for $72 \mathrm{~h}$. As shown in the figure a statistically significant rate of necrosis compared to controls, started with $4 \mu \mathrm{g} / \mathrm{mL}$ and with $20 \mu \mathrm{g} / \mathrm{mL}$ of GO a high percentage of cells floated in the media at $24 \mathrm{~h}$ and cellular debris were present at 48 and $72 \mathrm{~h}$ (not shown). 
Transmission Electron Microscopy (TEM) was performed to morphologically characterize the GO nanoribbons before adding them to the cultures. Characterization of nanoribbons by TEM showing structural integrity is reported in Figure 1A.

GO uptake was comparable in the two cell lines. Figure 1B shows that GO uptake for SK-N-BE(2) was at its maximum during the first $4 \mathrm{~h}$ of exposure, remained constant for $24 \mathrm{~h}$ and then decreased, while maximum uptake of GO in SH-SY5Y cells took place within $24 \mathrm{~h}$ and then started to decrease. Small amounts of GO were found in supernatants of both cell lines after $72 \mathrm{~h}$ of exposure, meaning that further acquisition of nanoparticles by the same cells was not possible.

TEM shows that GO was internalized in the cells and did not simply adhere to the cell membranes.

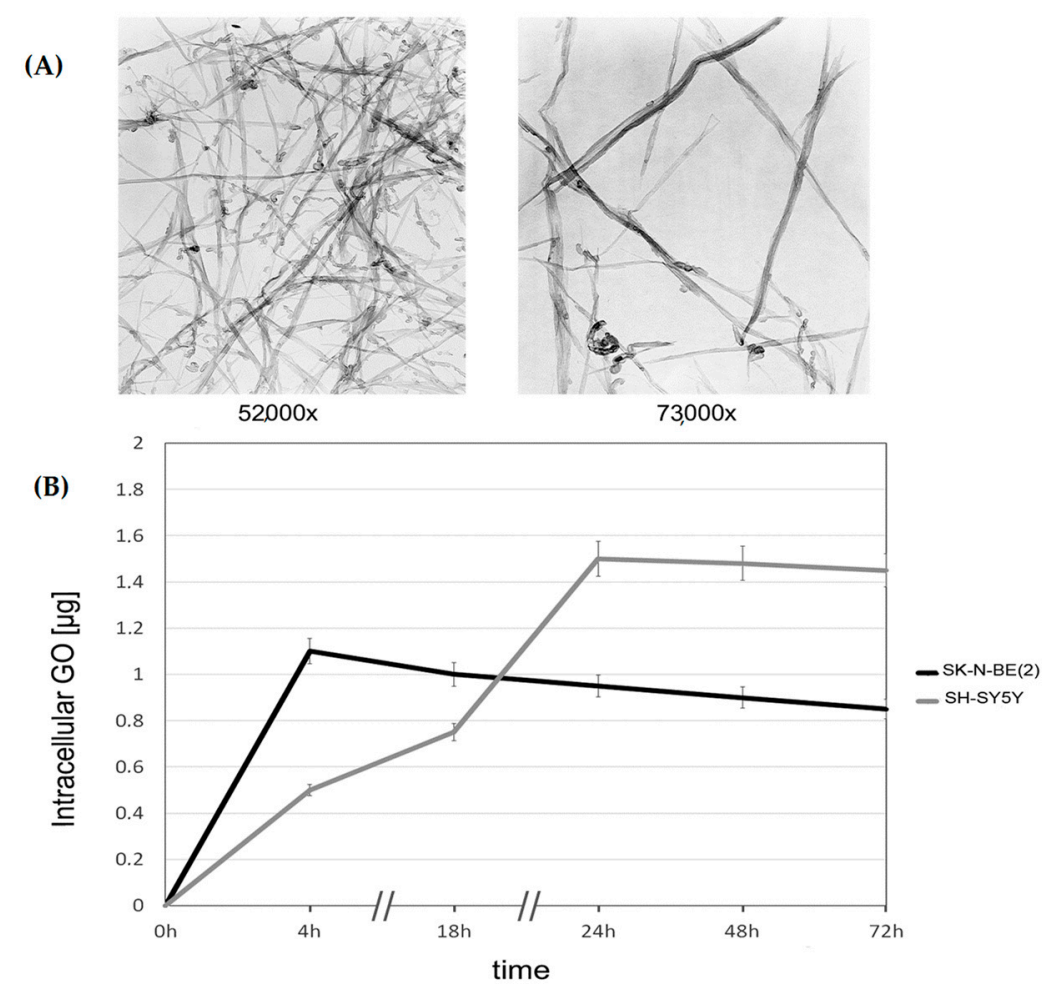

Figure 1. Uptake of graphene oxide (GO) nanoparticles: (A) characterization of nanoribbons by Transmission Electron Microscopy (TEM) (left: 52,000× magnification; right: 73,000 $\times$ magnification); and (B) uptake of GO nanoparticles in SK-N-BE(2) and SH-SY5Y cells in $72 \mathrm{~h}$. Data are obtained from spectophotometer readings (OD 340) of supernatants at different times. Concentrations of GO were obtained by subtracting amounts present in supernatants from an initial (T0) concentration of $2 \mu \mathrm{g} / \mathrm{mL}$.

Figure 2 shows interaction of GO in SK-N-BE(2) cells. After $18 \mathrm{~h}$ of GO exposure, (Figure 2a) two different dispositions of GO particles were observed. In particular, Figure $2 b$ shows single nanoribbons perpendicular to the plasmamembrane, whereas Figure $2 c$ shows large GO aggregates on the plasmamembrane. After $24 \mathrm{~h}$ single nanoribbons were found inside the cytoplasm and were not associated or interacting with autophagic vacuoles or lysosomes (Figure 2d). At the same time, however, phagosomes and autophagosomes containing GO aggregates were observed close to the plasmamembrane in GO treated cells (Figure 2e,f). The number of phagosomes, autophagosomes and autophago-lysosomes with GO cargo increased after 48 and $72 \mathrm{~h}$ of GO exposure (Figure 2g-i). 


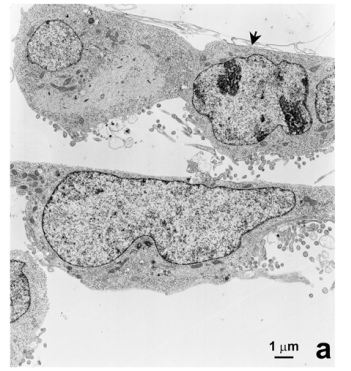

$18 \mathrm{~h}$
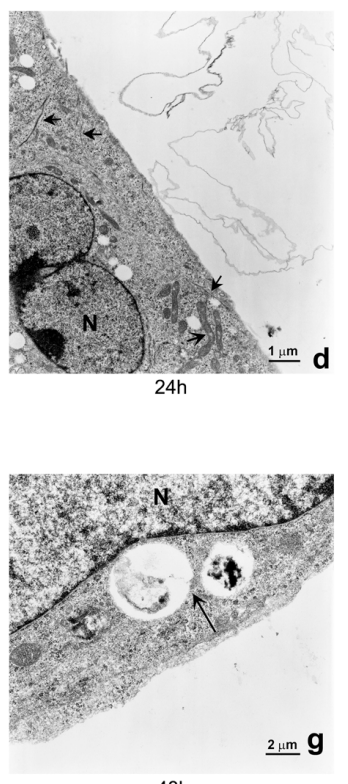

$48 \mathrm{~h}$
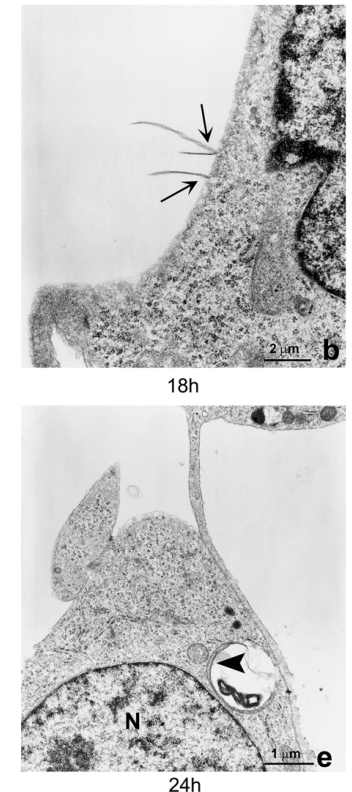

$24 \mathrm{~h}$

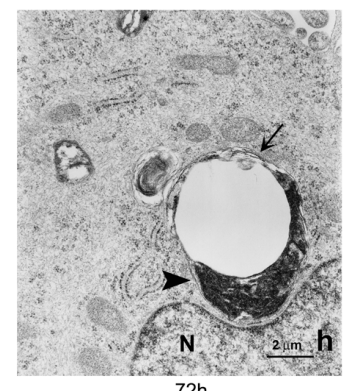

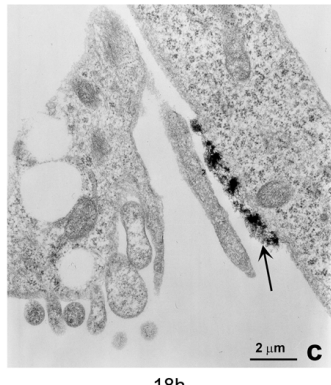

$18 \mathrm{~h}$
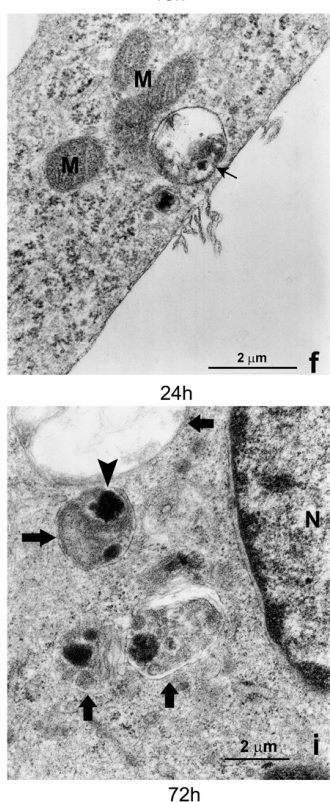

Figure 2. TEM images of GO-treated SK-N-BE(2) cells: (a) SK-N-BE(2) cells at low magnification showing normal nuclear and cellular morphology. No signs of ultra-structure alteration of sub-cellular compartments are visible. Interaction of GO nanoribbons with plasmamembrane are visible in the upper part of the image (arrow) (magnification 3800×); (b) Single GO nanoribbons interaction (arrow) with SK-N-BE(2) plasmamembrane after $18 \mathrm{~h}$ of exposure. Note the perpendicular orientation of GO (magnification 21,000×); (c) Large amounts of GO nanoparticles (arrow) interacting with the plasmamembrane and appearing like electron dense aggregates (magnification 21,000×); (d) Graphene single nanoribbons are present inside cytoplasm (arrows) after 24 h of exposure (magnification $6600 \times$ ). The image shows the presence of fused mitochondria (arrow); (e) Autophagosome (double membrane is showed by arrowhead) containing graphene visible like electron dense structure and localized inside the cell near the plasma membrane of SK-N-BE(2) cells after $24 \mathrm{~h}$ of incubation (magnification 11,500 $\times$ ); (f) Phagosome vacuole containing GO aggregates and localized near the plasmamembrane (arrow). Note the presence of GO sheets still interacting with the plasmamembrane (arrowhead) (magnification $39,000 \times)$; (g) SK-N-BE(2) at $48 \mathrm{~h}$ of GO exposure showing phagosomes vacuoles adjacent to the nuclear membrane (arrow) (magnification 15,500×); (h) autophago-lysosome with double membrane (arrow) and containing a large amount of graphene aggregates close to the nuclear membrane (arrowhead) (magnification 21,000×); (i) Seventy-two hours of exposure to GO $(28,500 \times$ ) induced autophagosomes accumulation $(28,500 \times)$. The image shows an increased number of autophagosomes containing electron dense GO aggregates (arrowhead) and with evident double membranes (arrows). Images were taken by using a Philips CM-10 Transmission Electron Microscopy as described under Materials and Methods. $\mathrm{N}=$ nucleus; $\mathrm{M}=$ mitochondria. 


\subsection{Cytotoxycity: Generation of Reactive Oxygen Species and Mitochondrial Membrane Potential}

GO induces production of reactive oxygen species (ROS) in SK-N-BE(2) cells and in SH-SY5Y cells in a time dependent manner. Figure 3 shows the time dependent curve of ROS generation in SK-N-BE(2) cells treated with GO at a concentration of $2.0 \mu \mathrm{g}$. Production of ROS in cells treated with GO increases in relation to the control after $30 \mathrm{~min}$ of exposure $(p=0.04)$. The increasing trend continues for up to $48 \mathrm{~h}$ ( $p=0.008$ at $4 \mathrm{~h}, p=0.002$ at $24 \mathrm{~h}, p=0.001$ at $48 \mathrm{~h}$ ) of GO exposure, while, at $72 \mathrm{~h}, \mathrm{ROS}$ production in treated cells decreases almost to control levels. JC1 dye ratio, which is used as an indicator of mitochondrial potential, started to decrease in SK-N-BE(2) cells after $4 \mathrm{~h}$ of treatment, probably as a result of ROS accumulation $(p=0.0001)$.
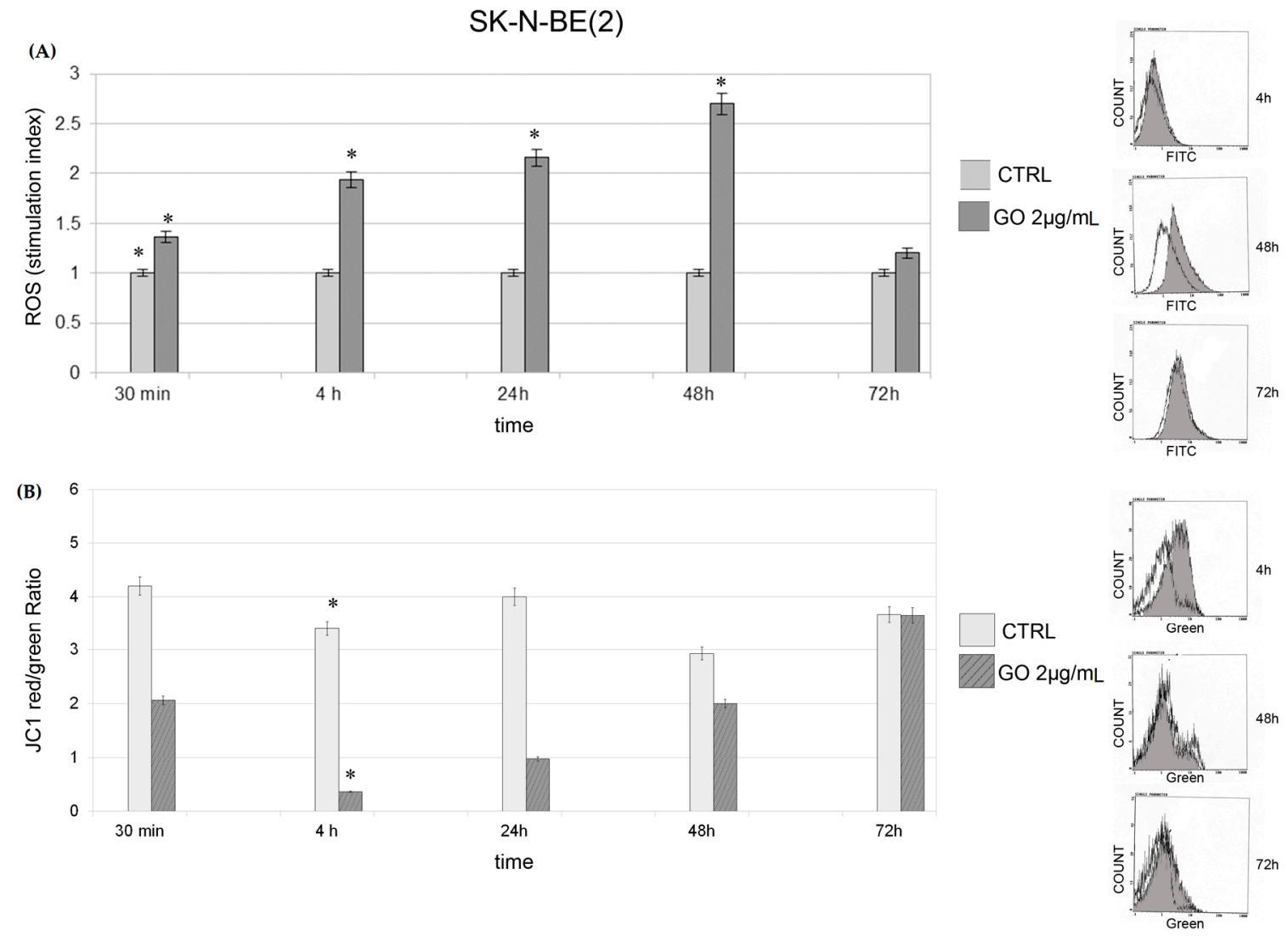

Figure 3. Reactive oxygen species (ROS) production and JC1 dye in SK-N-BE(2) cells: (A) ROS production in SK-N-BE(2) cells at different times of GO exposure The mean fluorescence intensity was detected and expressed as stimulation index obtained by ratio between ROS levels in treated cells divided by ROS in control cells. Data are the mean \pm SD of three different experiments. ${ }^{*} p<0.05$ for each exposure condition compared to unexposed control (CTRL). On the right of the panel, there are indicative fluorescence peaks (FITC) of control cells and GO treated cells at indicated times. Grey peaks refer to GO treated cells. (B) JC1 dye in SK-N-BE(2) cells at different times of GO exposure. Data are expressed as mean of red/green ratio of three different experiments \pm SD. On the right of the panel, there are indicative peaks of green fluorescence (referring to depolarized cells) of control cells and $\mathrm{GO}$ treated cells at indicated times. Grey peaks refer to GO treated cells. ${ }^{*} p<0.05$ for each exposure condition compared to unexposed control (CTRL).

A similar trend in production of ROS was also observed in SH-SY5Y cells (Figure 4). In SH-SY5Y cells, ROS production started to increase after $4 \mathrm{~h}$ of GO exposure compared with the controls, peaked at $24 \mathrm{~h}(p=0.03)$ and decreased at $48(p=0.04)$ and $72 \mathrm{~h}$. The increase in ROS parallels the decrease in JC1 ratio. 

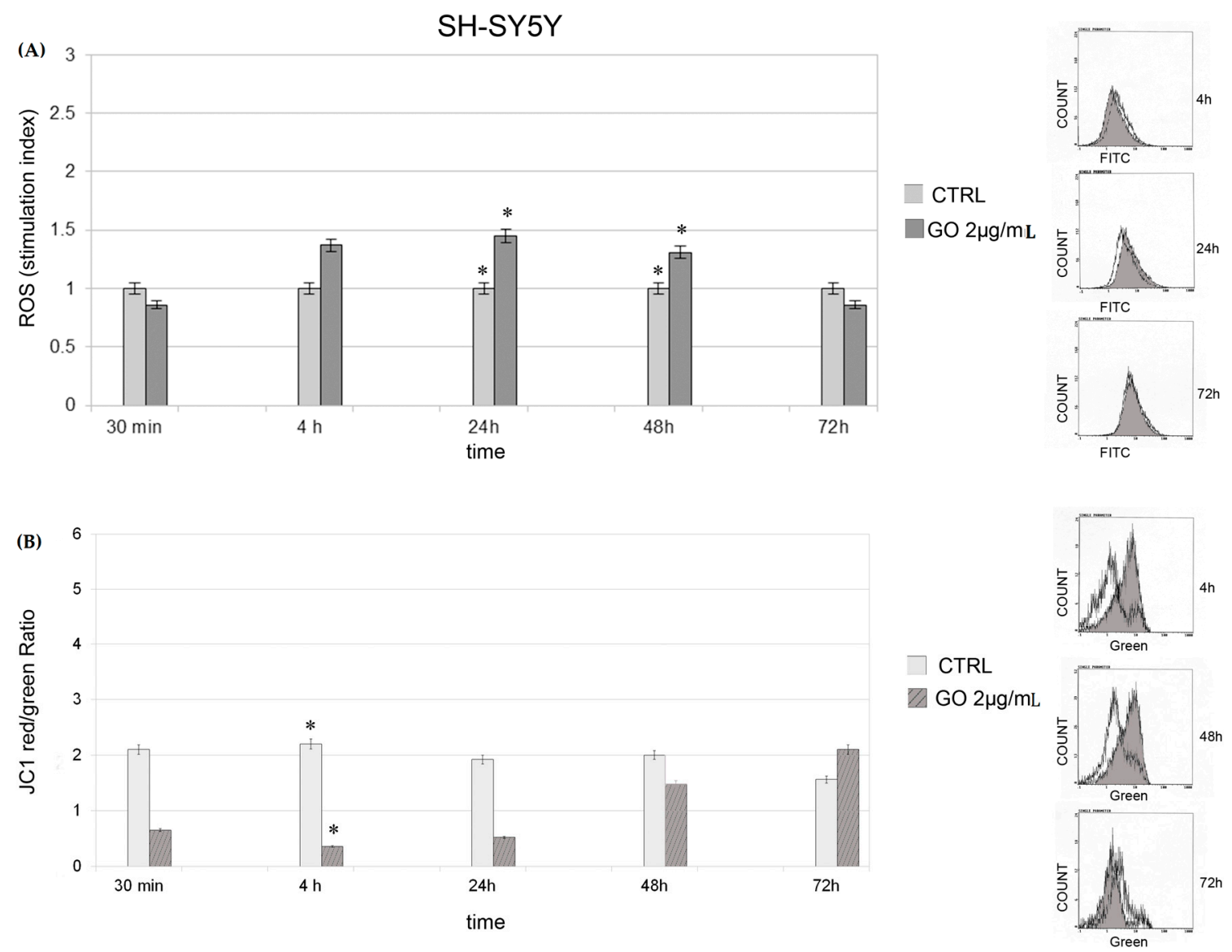

Figure 4. ROS production and JC1 dye in SH-SY5Y cells: (A) ROS production in SH-SY5Y cells at different times of GO exposure The mean fluorescence intensity was detected and expressed as stimulation index obtained by ratio between ROS levels in treated cells divided by ROS in control cells. Data are the mean $\pm S D$ of three different experiments. On the right of the panel, there are indicative fluorescence peaks of control cells and GO treated cells at indicated times. Grey peaks refer to GO treated cells. ${ }^{*} p<0.05$ for each exposure condition compared to unexposed control (CTRL). (B) JC1 dye in SH-SY5Y cells at different times of GO exposure. Data are expressed as mean of red/green ratio of three different experiments $\pm \mathrm{SD}$. On the right of the panel, there are indicative peaks of green fluorescence (referring to depolarized cells) of control cells and GO treated cells at indicated times. Grey peaks refer to graphene treated cells. ${ }^{*} p<0.05$ for each exposure condition compared to unexposed control (CTRL).

At $48 \mathrm{~h}$, TEM confirmed mitochondrial swelling and disorganization in SK-N-BE(2) cells (Figure 5a). After $48 \mathrm{~h}$, polymorphic as well as fused mitochondria with condensed conformation and decreased volume were observed in GO treated cells (Figure 5b). A large autophagosome containing disorganized mitochondria was found after $48 \mathrm{~h}$ of treatment (Figure 5c), probably due to induction of mitophagy. 

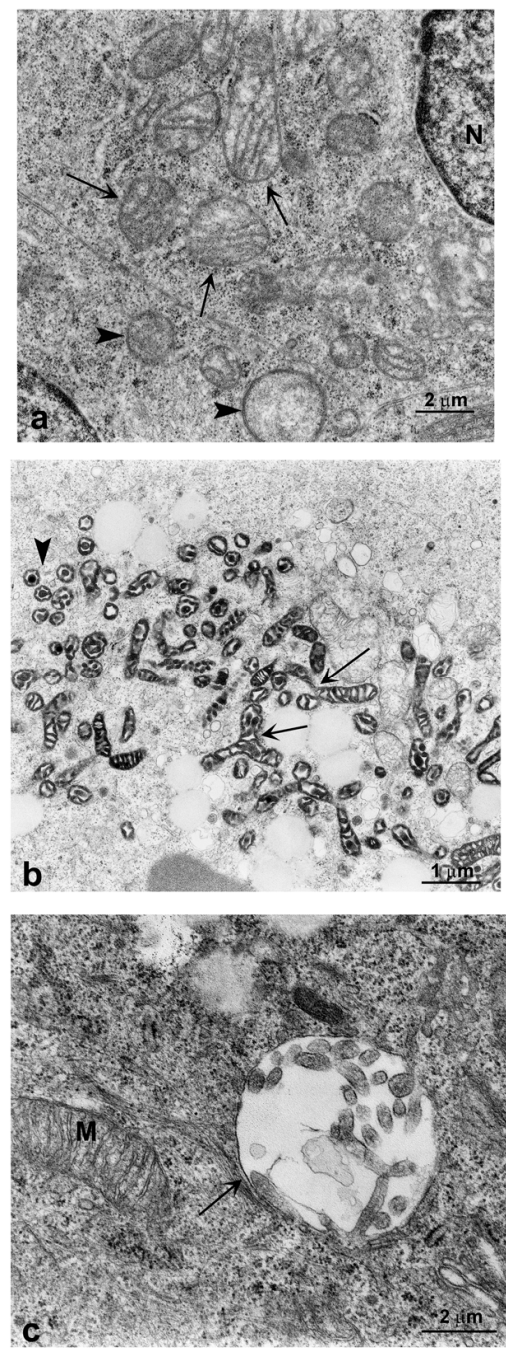

Figure 5. TEM images of autophagosomes in GO-treated SK-N-BE(2) cells: (a) SK-N-BE(2) cells at $48 \mathrm{~h}$ of GO treatment. Swollen mitochondria are visible. The matrix shows a decrease in electron density and an increase in volume. Sometimes the cristae appear disorganized (arrows). Disorganized mitochondria are also visible (arrowhead) $(21,000 \times)$; (b) At $72 \mathrm{~h}$ of GO treatment the mitochondria are polymorphic, in condensed conformation (low energy state and high level of oxidative phosphorylation) with high electron density and decreased volume, intramembranes and intracristal space. Some fused mitochondria are visible (arrows) $(11,500 \times)$; (c) Autophagosome (arrow) containing disorganized mitochondria (mitophagy) in SK-N-BE(2) cells at $72 \mathrm{~h}$ of incubation with GO $(28,500 \times)$. N = nucleus; $\mathrm{M}=$ mitochondria. Images were taken by using a Philips CM-10 Trasmission Electron Microscopy as described under Materials and Methods.

\subsection{Induction of Autophagy and Mitophagy in Cells Treated with GO}

In the first steps of autophagy [14], beclin 1 protein forms a complex with Atg14, Vps34/PI3k and Vps15 that is essential for autophagosome formation. Induction of autophagy is clearly demonstrated in our experimental model in both cell lines by the increased expression of beclin 1 after $24 \mathrm{~h}$ of exposure to GO. Figure 6 shows that Beclin 1 is more expressed in SK-N-BE(2) cells than in SH-SY5Y cells $(p=0.004)$ and that GO is able to induce a progressively higher expression of beclin 1 , with a peak at $48 \mathrm{~h}(p=0.001)$. Interestingly there is a decrease in expression at $72 \mathrm{~h}$ in both cell lines. LC 3 is a structural component of autophagosomes [15]. LC3 I is a soluble form (18 $\mathrm{kDa})$, while LC3 II is the autophagosome membrane bound form $(16 \mathrm{kDa})$. As well as beclin 1, both components of LC3 protein increase for $48 \mathrm{~h}$ in both cell lines and decrease after $72 \mathrm{~h}$ of graphene exposure (Figure 6). 


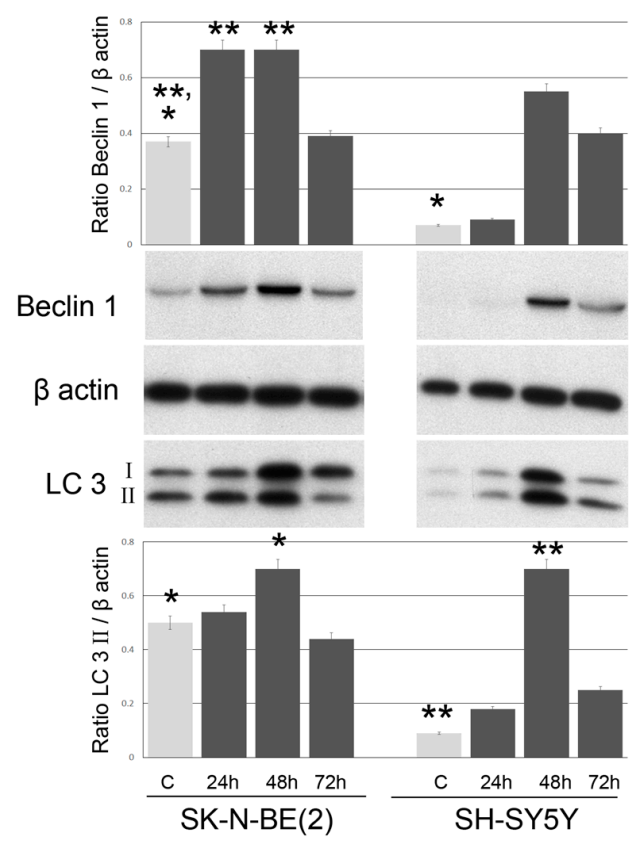

Figure 6. Expression levels of beclin 1 and LC3 in SK-N-BE(2) cells and SH-SY5Y. Representative experiment of three different Western blots of Beclin 1 (52 kDa), LC3 I (18 KDa) and LC3 II (16 KDa) in SK-N-BE(2) cells and SH-SY5Y at different times of incubation with GO. Proteins were detected by Western blot in whole cell lysates. Densitometry was performed on bands and results are expressed as ratio protein $/ \beta$ actin. Histograms represent the mean values of three independent experiments \pm SD. * and ${ }^{* *} p<0.05$ for each exposure time compared to unexposed control (CTRL).

Because the presence of some vacuoles containing mitochondria and dysfunctional mitochondria, which is considered an index of mitophagy [16], was observed (Figure 5c), we analyzed the expression of BNIP 3, which is prominently regulated at the transcriptional level in autophagosomes containing mitochondria during stressful conditions such as hypoxia [17]. As shown by Western blot in Figure 7, BNIP 3 receptor is induced by GO in both cell lines after $24 \mathrm{~h}$ of exposure, is at its maximum at $48 \mathrm{~h}$ and decreases at $72 \mathrm{~h}$.

A)

BNIP-3

$\beta$-actin

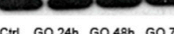

SK-N-BE(2)

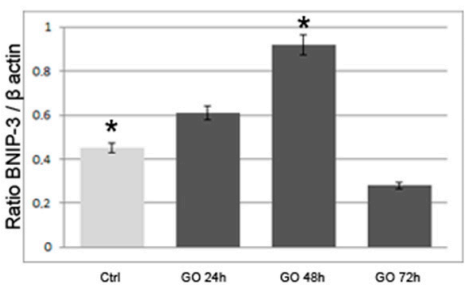

B)

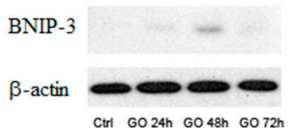

SH-SY5Y

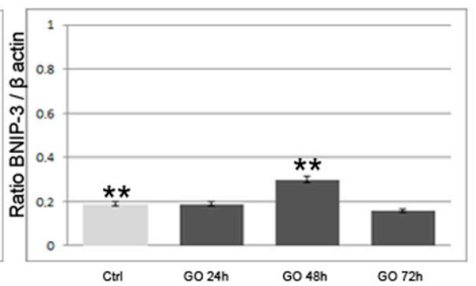

Figure 7. Expression of BNIP 3 in SK-N-BE(2) and SH-SY5Y. cells: (A) BNIP 3 (22 and $30 \mathrm{kDa}$ ) in SK-N-BE(2) and SH-SY5Y; and (B) at different times of incubation with GO. Densitometry was performed on bands and results are expressed as ratio protein/ $\beta$ actin. Histograms represent the mean values of three independent experiments $\pm \mathrm{SD}$. ${ }^{*}$ and ${ }^{* *} p<0.05$ for each exposure time compared to unexposed control (CTRL). 


\subsection{Evaluation of Cellular Proliferation}

Cell growth curves in Figure 8 shows that in both cell lines there was a decrease in growth rate during exposure to GO for up to $48 \mathrm{~h}$ compared to controls, more evident in SK-N-BE(2) than in SH-SY5Y. Interestingly, between 48 and $72 \mathrm{~h}$, there was a resumption of growth in both cell lines treated with GO $2 \mu \mathrm{g} / \mathrm{mL}$. This means that, although cells undergo stress with induction of autophagy, they recover and are still able to grow. This is confirmed by the fact that when cells treated with GO for $72 \mathrm{~h}$ were allowed to grow in fresh medium for further $48 \mathrm{~h}$, there was no significant difference in growth rate compared with controls (Figure 8, at 96 and $120 \mathrm{~h}$ ).

(A)

\section{SK-N-BE(2)}

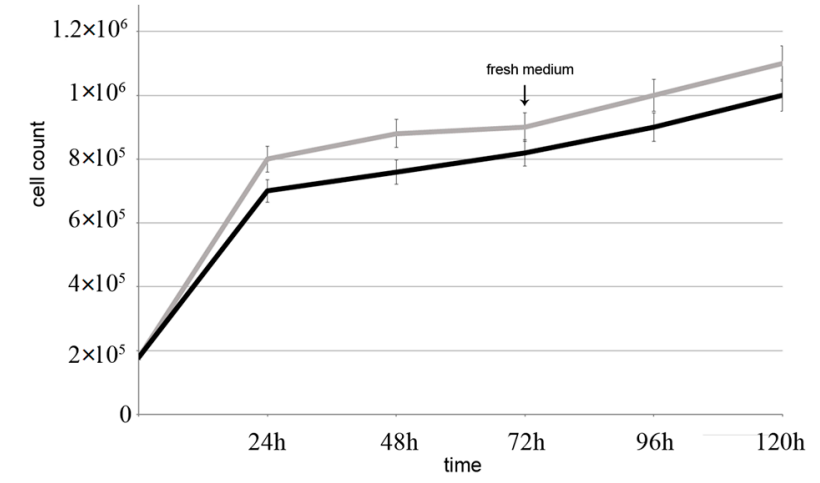

SH-SY5Y

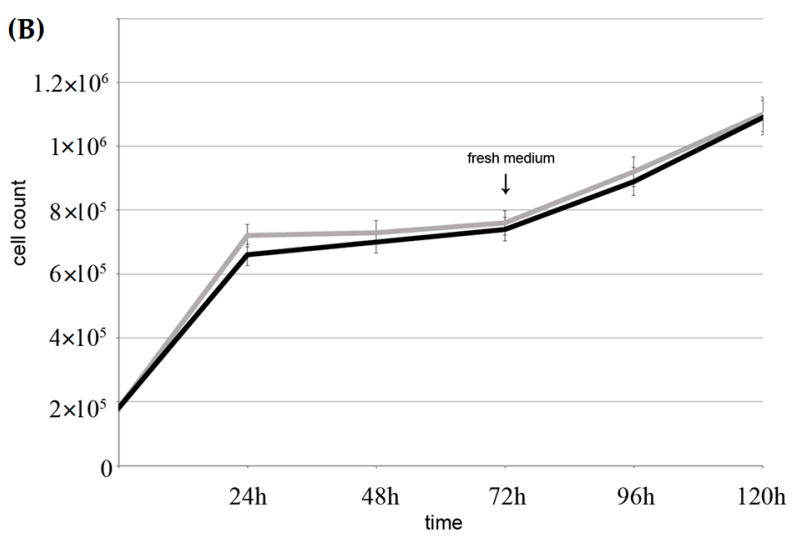

Figure 8. Growth curves of SK-N-BE(2) and SH-SY5Y cells: SK-N-BE(2) (A) cells; and SH-SY5Y cells (B) were treated with GO $(2.0 \mu \mathrm{g} / \mathrm{mL})$ for up to $72 \mathrm{~h}$. Medium was changed at $72 \mathrm{~h}$ and cultures were allowed to grow for 96 and $120 \mathrm{~h}$. At the end of incubation time, cells were stained with Trypan blue dye and counted on a hemocytometer. Data are mean of three independent experiments \pm SD.

\section{Discussion}

In this study the cytotoxicity of GO nanoribbons in two neuroblastoma cell lines was assessed. It shows that GO nanoribbons enter the cells and two different dispositions of the nano particles within $24 \mathrm{~h}$ of exposure on the plasmamembranes, i.e., as single perpendicular nanoribbons or electron dense GO aggregates. This suggests either that GO can enter the cells by interacting with the plasmamembrane and probably temporarily disrupting the phospholipid bilayer, or that GO can cause plasmamembrane invagination. Disruption of the phospholipid bilayer following GO treatment has already been documented in Hep G2 cells, although authors could not conclude whether or not the damage depended on the orientation of the nanoparticles [18]. Entrance of nanoparticles into cells, 
apart from phagocytes, has been a concern for many researchers, as most studies on cytotoxicity of nano-diamonds, for example, have not been able to decide if particles were inside cells or aggregated on plasmamembranes [19].

Interestingly, in the present study, at $24 \mathrm{~h} \mathrm{GO}$ particles are found both as single layer nanoribbons inside the cytoplasm and as aggregates in vacuoles localized close to the plasmamembrane. Finally, after $48 \mathrm{~h}$, we observed an increase in autophagosomes and autophago-lysosomes containing GO aggregates and close to the nucleus. Entrance of GO nanoribbons and vacuolation was more evident in SK-N-BE(2) cells than in SH-SY5Y cells. This can be explained by the different morphology of SH-SY5Y cells and the tendency of the GO nanoparticles to localize in proximity to the cell body instead of the protrusions, as already shown in glioma cells with different physical forms of GO [12]. SH-SY5Y cells display a higher number of dendrites on their surface than SK-N-BE(2) cells and GO uptake in these cells is heterogeneous; it probably does not enter every cell at the same time. That GO nanoparticles enter SH-SY5Y cells is shown by the higher production of ROS and mitochondrial membrane perturbation from 4 to $48 \mathrm{~h}$ of GO exposure. Other authors have reported that GO nanosheets bound to retinoic acid induce dendritic elongation in SH-SY5Y cells, meaning that GO uptake is constant in this cell line [20]. Regarding ROS increased levels, our results are not consistent with those reported by other authors in other cell lines [18] because we report an increase in ROS at very low doses and after only brief exposure to GO. We would add here that both ROS production and mitochondrial depolarization tend to normalize at $72 \mathrm{~h}$ of exposure. Apoptosis and inflammatory response have been shown in macrophages treated with graphene quantum dots [21]. On the other hand, GO nanoparticles at low dosages have been shown not to induce apoptosis [22,23].

Our study shows that GO nanoribbons at low concentrations and within $72 \mathrm{~h}$ of exposure induce autophagy in neuroblastoma cell lines. This is demonstrated by the presence of cytoplasmic vacuoles, especially in treated SK-N-BE(2) cells, and by the induction of the lysosomal protein LC3 and beclin, which are markers of autophagy $[24,25]$. Finally, mitophagy (shown in Figures $5 c$ and 7 ) induced by treatment with GO for $48 \mathrm{~h}$ in SK-N-BE(2) cells was observed, probably as a response to ROS increase, as previously reported. Cell membranes were intact during treatment with graphene for up to $72 \mathrm{~h}$, there were not significant differences in the release of LDH during the $72 \mathrm{~h}$ of exposure to GO $(2 \mu \mathrm{g} / \mathrm{mL})$ (not shown) other signs of necrosis or necroptosis have never been found in ultrastructural studies.

Autophagy is a multistep, dynamic process which begins with the formation of the double membrane autophagosome, that engulfs a part of cytoplasm and organelles. This process is very rapid and leads to the formation of an autolysosome whose enzymes digest their content [26]. Autophagy is thus considered a double-edged sword for tumor cells, since it stops cell proliferation but also preserves tumor phenotypes by preserving organelles and preventing cell death [27]. The present study provides the first evidence that cells respond in vitro, directly and within hours, to low doses of GO nanoribbons by promoting vacuolation and mitophagy. We also identified through TEM that vacuoles were derived from the autophagic pathway, since they had double membranes and contained organelles. Moreover, treated cells over-expressed both the early marker of autophagosomes beclin and the late LC3 II phagolysosome marker. We also report that the mitophagy marker BNIP 3 [28-30] is more strongly expressed within $48 \mathrm{~h}$ of GO exposure in both cell lines and its expression decreases at $72 \mathrm{~h}$. This is compatible with the existence of compensatory mechanisms that take place after cells have destroyed damaged mitochondria. In fact our results show that in neuroblastoma cell lines, GO induces initial oxidative stress and mitochondrial damage, to which cells respond by activating the autophagic/mitophagic process in order to remove damaged proteins and mitochondria. Execution of autophagy/mitophagy starts at 24 and continues up to $72 \mathrm{~h}$ (Figures 2, 5 and 7), after which cells recover and continue to grow (Figure 8).

Another interesting finding is that GO nanoribbons are not nucleotropic, since they were not found inside the cell nucleus. This must be taken into account if GO has to be used to carry drugs that target DNA [31]. The size and initial carbon source are also important, as they may affect biocompatibility and cellular uptake [32]. It should be pointed out that the nanoribbons we used had 
a very thin diameter and did not cause permanent disruption or invagination of plasmamembranes at the used concentrations. In fact, it has been documented that the treated cells can initiate metabolic and energy-dependent processes aimed at repairing the damaged plasmamembrane and reconstituting cell integrity. However, orientation of nanoparticles seemed important in our study. As Figure 2 shows, after GO exposure, nanoribbons were seen interacting with plasmamembranes and in an initial phase of the internalization process they were localized in the cytosol and so, were free to interact with organelles. In a subsequent phase, nanoribbons were included in phagosomes that fused with lysosomes. GO particles were observed inside vacuoles after $48 \mathrm{~h}$. In spite of the fact that ROS and JC1 decreased and cells were growing at $72 \mathrm{~h}$, the number of vacuoles increased, localized near the nucleus and contained GO aggregates, demonstrating that autophagy had been activated to remove or metabolize the GO nanoparticles; the latter observation needs further confirmation in various cell lines. The finding that Beclin, LC3 II and BNIP 3 decrease at $72 \mathrm{~h}$ while vacuoles observed in TEM increase in number, can be explained by the fact that while on the one hand the cell is eliminating its damaged organelles and expressing autophagy markers, on the other it is recovering from stress and growing. Cell growth rate was not affected by GO treatment in cultures that had fresh medium replaced for up to $120 \mathrm{~h}$, meaning that cells recovered from initial stress would be able to tolerate a new administration of the drug-carrier.

In conclusion, we believe that GO has good potentials as a drug delivery system in neuroblastoma, as it is internalized by the two different neuroblastoma cell types and could prove very useful for carrying drugs that target cytoplasmic functions (i.e., microRNAs).

\section{Materials and Methods}

\subsection{Synthesis of GO Nanoribbons}

GO nanoribbons were obtained using a Hummer modified method from nanotubes (SWNCTs) (Carbolex AP-Grade-Sigma-Aldrich, St. Louis, MO, USA). Briefly, single-wall carbon nanotubes (SWCNTs) $(100 \mathrm{mg} / 100 \mathrm{~mL})$ were dispersed in a concentrated solution of $\mathrm{HNO}_{3} / \mathrm{H}_{2} \mathrm{SO}_{4}(1: 3)$ and sonicated for $8 \mathrm{~h}$ at $50 \mathrm{~W}$ at $45^{\circ} \mathrm{C}$. This treatment produced long, thin GO nanoribbons as reported in [33].

Raman spectroscopy and FT-IR spectroscopy on the final product is shown in previous paper $[33,34]$. Zeta potential for $\mathrm{GO}$ nanoribbons was $-16 \mathrm{mV}$. The $Z$ potential measurements were carried out by using a Zetasizer Nano ZS equipment (Malvern, UK). This apparatus is combined with a back scattering detection mode (with an angle of $173^{\circ}$ ), and a laser He-Ne having $633 \mathrm{~nm}$ as wavelength (Laser Doppler Velocimetry). The PALS (Phase Analysis Laser Light Scattering) was used for the signal collection and elaboration. The cells used for the Zeta potential analysis containing two gold/Au conventional electrodes.

Nanoribbons (diameter $22-26 \mathrm{~nm}$ ) were washed in ultra-pure $\mathrm{H}_{2} \mathrm{O}$ and dried in an oven at $100{ }^{\circ} \mathrm{C}$. GO suspension was dispersed in distilled $\mathrm{H}_{2} \mathrm{O}$ at a concentration of $1 \mathrm{mg} / \mathrm{mL}$ and sonicated for $2 \mathrm{~h}$ in a $4.25 \mathrm{~L}$ bath type ultrasonic unit (Bransonic 220, Branson, MO, USA)

Following sonication, the suspensions were centrifuged at $1300 \times g$ for $30 \mathrm{~min}$ and the supernatants transferred to fresh tubes. GO concentration in cell supernatants was estimated using a concentration absorbance standard curve generated from aliquots of the original, non-centrifuged suspension and of serial dilutions. Absorbance measurements were performed in a spectrophotometer (Jenway Genova, Stafford, UK) equipped with a $340 \mathrm{~nm}$ filter.

\subsection{Cell Culture}

The long term neuroblastoma cell lines, SK-N-BE(2) and SH-SY5Y, obtained from DSMZ, Braunschweig, Germany, SK-N-BE(2) (ACC No 632; SH-SY5Y ACC No. 209) in October 2012 were maintained in RPMI 1640 (GIBCO, Grand Island, NY, USA) with or without phenol red, supplemented with heat inactivated 10\% FCS containing $2 \mathrm{mM}$ L-glutamine. When indicated, $2.0 \mu \mathrm{g} / \mathrm{mL}$ of GO was added to the cultures at different times. Preliminary time and concentration course experiments 
with $0.2,2,4,10$ and $20 \mu \mathrm{g} / \mathrm{mL}$ of GO were performed in our laboratory in order to establish the conditions at which GO did not cause cell necrosis. Cell vitality was monitored before each experiment by Trypan blue (Sigma-Aldrich) [35] exclusion assay, in which dead cells are stained and those with intact membranes are not.

The unique feature of graphene composites is that they have many functional groups to which a large number of biological molecules can be bound. Thanks to this property, very low concentrations of GO need to be used. GO samples were sonicated for $1 \mathrm{~h}$ at $50 \mathrm{w}$ before adding to cell cultures.

Cells were kept frozen in nitrogen liquid tanks $\left(2 \times 10^{6} / \mathrm{mL} \mathrm{FCS,} \mathrm{10 \%} \mathrm{DMSO)} \mathrm{and} \mathrm{used} \mathrm{between}\right.$ the 4 th and 8 th passage after revival.

\subsection{GO Uptake in Cells}

Cells $\left(10^{5} / \mathrm{mL}\right.$ ) were seeded into 6-well plates (Corning Inc., Corning, NY, USA), allowed to attach for up to $6 \mathrm{~h}$, cultured in RPMI 1640 without phenol red and supplemented with GO for 24, 48 and $72 \mathrm{~h}$. At the end of incubation time, supernatants were collected and read with a spectrophotometer (Jenway Genova, Stafford, UK) at $340 \mathrm{~nm}$. GO concentration was calculated by readings at $340 \mathrm{~nm}$ and compared with the standard curve. Uptake was calculated by subtracting the amount of GO found in supernatants from the amount added at time 0 .

\subsection{Transmission Electron Microscopy Analysis}

For TEM characterization, GO nanoribbons from SWNCTs were centrifuged at $1300 \times g$ for $30 \mathrm{~min}$. The resulting supernatant was diluted $(0.01 \mathrm{mg} / \mathrm{mL})$, precipitated on copper grids and dried overnight. TEM imaging was performed using a Philips CM-10 Transmission Electron Microscope (FEI, Hamilton, ON, Canada) microphotographs were recorded on Kodak 4489 sheet film.

SK-N-BE(2) and SH-SY5Y cell lines were scraped and pelleted. Cell pellets were then suspended and fixed overnight at $4{ }^{\circ} \mathrm{C}$ with $2.5 \%$ glutaraldehyde in $0.1 \mathrm{M}$ phosphate buffer $\mathrm{pH} 7.3$, washed six times in PBS and then post-fixed in 1.33\% osmium tetroxide in the same buffer for $1 \mathrm{~h}$ at room temperature. Cells were dehydrated in increasing graded steps of ethanol and embedded in epoxy resin (Embed 812, Electron Microscopy Science, Perth, Australia). The polymerization was performed at $60{ }^{\circ} \mathrm{C}$ for $24-48 \mathrm{~h}$. Ultra-thin sections $(60-70 \mathrm{~nm})$ were cut on a Reichert-Jung, Buffalo, USA, ultramicrotome (Leica Microsistems, Wetzlar, Germany) and picked up on copper grids. Sections were post-stained with uranyl acetate and lead hydroxide and then analyzed using a Philips CM-10 Trasmission Electron Microscopy (FEI, Hamilton, ON, Canada); micrographs were recorded on Kodak 4489 sheet film.

\subsection{Western Blot}

Whole cell lysates were separated as previously described [36] on $10 \%$ or $15 \%$ SDS-polyacrilamide electroforesis gel respectively for Beclin 1 (Cell Signaling, Danvers, MA, USA) used at a final concentration of 1:1000, LC3 (Novus, Cambridge, UK) used at a final concentration of 1:2000, and BNIP 3 (Santa Cruz Biotechnology, Santa Cruz, TX, USA) used at a final concentration of 1:500. Samples were heat denatured for $5 \mathrm{~min}$, loaded on standard Tris- $\mathrm{HCl}$ polyacrylamide gel and run on ice at $40 \mathrm{~V}$ for the stacking gel and $80 \mathrm{~V}$ for the running gel. Proteins were transferred onto a previously activated PVDF membrane (Bio-Rad, Hercules, CA, USA). Membranes were then placed in TBS-T and $5 \%$ albumin for $1 \mathrm{~h}$ and probed overnight with the specific antibody at $4{ }^{\circ} \mathrm{C}$. At the end of incubation time, membranes were washed and incubated with anti-mouse IgG (Cell Signaling, MA, USA) peroxidase conjugated secondary antibody $(1: 10,000)$ for $1 \mathrm{~h}$ at room temperature. Membranes were stripped and incubated with anti-actin monoclonal antibody (Sigma-Aldrich) as a loading control. Signal was detected by autoradiography (Kodak Biomax, Sigma-Aldrich) using the chemiluminescent peroxidase substrate kit (Sigma-Aldrich) then quantified by densitometric analysis using Quantity One software (Bio-Rad). 


\subsection{Reactive Oxygen Species (ROS) Detection}

ROS formation in both cell lines treated or not with GO $2.0 \mu \mathrm{g} / \mathrm{mL}$ was assayed by flow cytometry using the dye DCF-DA (dichlorofluorosceine-diacetate) and following standard methods [37,38]. Briefly, DCF-DA (final concentration $40 \mu \mathrm{M}$ ) was added to cell cultures on 6 wells plates for 15 min at $37^{\circ} \mathrm{C}$. After incubation time, cells were treated with GO $2.0 \mu \mathrm{g} / \mathrm{mL}$ at different times. At the end of incubation time, cells were scraped, washed in PBS and analyzed by flow cytometer (Epics XL-MCL Coulter, CA, USA) equipped with an Argon laser at $488 \mathrm{~nm}$. Cells were gated on the basis of forward angle light-scatter (FS) and $90^{\circ}$ light scatter parameters (SS). For every histogram a minimum of 20,000 events were counted. The mean fluorescence intensity was detected and expressed as percentage of relative ROS level versus control cells.

\subsection{JC1 Mitochondrial Membrane Potential Assay}

The mitochondrial membrane potential (MMP) was determined using JC1 dye [39]. Following different times of exposure to GO $2.0 \mu \mathrm{g} / \mathrm{mL}$, the cells were washed and fresh medium was replaced. JC1 (final concentration $1.25 \mu \mathrm{g} / \mathrm{mL}$ ) was added for $30 \mathrm{~min}$ at $37^{\circ} \mathrm{C}$. After incubation cells were washed three times with PBS at $4{ }^{\circ} \mathrm{C}$ and the red substrate fluorescence intensity was read at 544 and $590 \mathrm{~nm}$ (excitation-emission) in a cytofluorimeter. For every histogram, a minimum of 20,000 events were counted. Results are expressed as the percentage of red/green fluorescence value compared with the control.

\subsection{Statistical Analysis}

Statistically significant differences were determined using KaleidaGraph version 4.5.1 Synergy Software (Macintosh) PA, USA. Results are expressed as means \pm standard deviations (SD). Student's $t$-test was used to determine significant differences at $p$-value of 0.05 . Asterisks shown in figures indicate significant differences between exposed and unexposed to GO cell populations.

Supplementary Materials: Supplementary materials can be found at www.mdpi.com/1422-0067/17/12/1995/s1.

Acknowledgments: The authors would like to thank Elisa La Preziosa for her help in synthesizing the GO nanoribbons, Hugo Bowles (University Tor Vergata, Rome) for proofreading, Ivo Nestola for his help with graphics and Evarist Granata of the GranHub for financial help. This work was supported by grants Ateneo 2011 to Alessandra Zicari, Ateneo 2015 to Marco Tafani and RF-2011-02349126 from Italian Ministry of Health.

Author Contributions: Emanuela Mari and Stefania Mardente designed the work, performed the experiments, and wrote the paper; Emanuela Morgante designed, performed the TEM studies and wrote the paper; Marco Tafani interpreted the data, critically revised the manuscript and wrote the paper; Emanuela Lococo performed the cytofluorimetric analyses and wrote parts of the paper; Flavia Fico performed the experiments on GO cellular uptake and growth, collected, analyzed and interpreted the data; Federica Valentini synthesized the GO and wrote parts of the paper; and Alessandra Zicari designed the work, interpreted the data and wrote the paper.

Conflicts of Interest: The authors declare no conflict of interest.

\section{References}

1. Cicchetti, R.; Divizia, M.; Valentini, F.; Argentin, G. Effects of single-wall carbon nanotubes in human cells of the oral cavity: Geno-cytotoxic risk. Toxicol. In Vitro 2011, 25, 1811-1819. [CrossRef] [PubMed]

2. Khodabandehloo, H.; Zahednasab, H.; Hafez, A.A. Nanocarriers usage for drug delivery in cancer therapy. Iran. J. Cancer Prev. 2016, 9, e3966. [CrossRef] [PubMed]

3. Valentini, F.; Carbone, M.; Palleschi, G. Carbon nanostructured materials for applications in nano-medicine, cultural heritage, and electrochemical biosensors. Anal. Bioanal. Chem. 2013, 405, 451-465. [CrossRef] [PubMed]

4. Pietroiusti, A.; Massimiani, M.; Fenoglio, I.; Colonna, M.; Valentini, F.; Palleschi, G.; Camaioni, A.; Magrini, A.; Siracusa, G.; Bergamaschi, A.; et al. Low doses of pristine and oxidized single-wall carbon nanotubes affect mammalian embryonic development. ACS Nano 2011, 5, 4624-4633. [CrossRef] [PubMed]

5. Maris, J.M. Recent advances in neuroblastoma. N. Engl. J. Med. 2010, 362, 2202-2211. [CrossRef] [PubMed] 
6. Samaraweera, L.; Grandinetti, K.B.; Huang, R.; Spengler, B.A.; Ross, R.A. MicroRNAs define distinct human neuroblastoma cell phenotypes and regulate their differentiation and tumorigenicity. BMC Cancer 2014, 14, 309-320. [CrossRef] [PubMed]

7. Brodeur, G.M.; Iyer, R.; Croucher, J.L.; Zhuang, T.; Higashi, M.; Kolla, V. Therapeutic targets for neuroblastomas. Exp. Opin. Ther. Targets 2014, 18, 277-292. [CrossRef] [PubMed]

8. Cossu, I.; Bottoni, G.; Loi, M.; Emionite, L.; Bartolini, A.; di Paolo, D.; Brignole, C.; Piaggio, F.; Perri, P.; Sacchi, A.; et al. Neuroblastoma-targeted nanocarriers improve drug delivery and penetration, delay tumor growth and abrogate metastatic diffusion. Biomaterials 2015, 68, 89-99. [CrossRef] [PubMed]

9. Allavena, P.; Mantovani, A. Immunology in the clinic review series; focus on cancer: Tumour-associated macrophages: Undisputed stars of the inflammatory tumour microenvironment. J. Transl. Immunol. 2011, 167, 195-205. [CrossRef] [PubMed]

10. Yuan, Y.; Zhang, Y.; Liu, B.; Wu, H.; Kang, Y.; Li, M.; Zeng, X.; He, N.; Zhang, G. The effects of multifunctional miR-122-loaded graphene-gold composites on drug-resistant liver cancer. J. Nanobiotechnol. 2015, 13, 12. [CrossRef] [PubMed]

11. Rezaei, A.; Akhavan, O.; Hashemi, E.; Shamsara, M. Toward chemical perfection of graphene-based gene carrier via Ugi multicomponent assembly process. Biomacromolecules 2016, 17, 2963-2971. [CrossRef] [PubMed]

12. Jaworski, S.; Sawosz, E.; Grodzik, M.; Winnicka, A.; Prasek, M.; Wierzbicki, M.; Chwalibog, A. In vitro evaluation of the effects of graphene platelets on glioblastoma multiforme cells. Int. J. Nanomed. 2013, 8, 413-420.

13. Lammel, T.; Boisseaux, P.; Fernàndez-Cruz, M.L.; Navas, J.M. Internalization and cytotoxicity of graphene oxide and carboxyl graphene nanoplatelets in the human hepatocellular carcinoma cell line Hep G2. Part. Fibre Toxicol. 2013, 10, 27. [CrossRef] [PubMed]

14. Miracco, C.; Cosci, E.; Oliveri, G. Protein and mRNA expression of autophagy gene Beclin 1 in human brain tumours. Int. J. Oncol. 2007, 30, 429-436. [PubMed]

15. Hanna, R.A.; Quinsay, M.N.; Orogo, A.M.; Giang, K.; Rikka, S.; Gustafsson, A.B. Microtubule-associated protein 1 light chain 3 (LC3) interacts with BNIP3 protein to selectively remove endoplasmic reticulum and mitochondria via autophagy. J. Biol. Chem. 2012, 287, 19094-19104. [CrossRef] [PubMed]

16. Hamacher-Brady, A.; Brady, N.R. Mitophagy programs: Mechanism and physiological implications of mitochondrial targeting by autophagy. Cell. Mol. Life Sci. 2016, 73, 775-795. [CrossRef] [PubMed]

17. Klionsky, D.J.; Abdalla, F.C.; Abeliovich, H.; Abraham, R.T.; Acevedo-Arozena, A.; Adeli, K.; Agholme, L.; Agnello, M.; Agostinis, P.; Aguirre-Ghiso, J.A.; et al. Guidelines for the use and interpretation of assays for monitoring autophagy (3rd Edition). Autophagy 2016, 12, 1-222. [CrossRef] [PubMed]

18. Yuan, J.; Gao, H.; Sui, J.; Duan, H.; Chen, W.N.; Ching, C.B. Cytotoxicity evaluation of oxidized single-walled carbon nanotubes and graphene oxide on human hepatoma HepG2 cells: An iTRAQ-coupled 2D LC-MS/MS proteome analysis. Toxicol. Sci. 2012, 126, 149-161. [CrossRef] [PubMed]

19. Zakrzewska, K.E.; Samluk, A.; Wierzbicki, M.; Jaworski, S.; Kutwin, M.; Sawosz, E.; Chwalibog, A.; Pijanowska, D.G.; Pluta, K.D. Analysis of the cytotoxicity of carbon-based nanoparticles, diamond and graphite, in human glioblastoma and hepatoma cell line. PLoS ONE 2015, 10, e0122579. [CrossRef] [PubMed]

20. Lv, M.; Zhang, Y.; Liang, L.; Wei, M.; Hu, W.; Li, X.; Huang, Q. Effect of graphene oxide on undifferentiated and retinoic acid-differentiated SH-SY5Y cells line. Nanoscale 2012, 4, 3861-3866. [CrossRef] [PubMed]

21. Qin, Y.; Zhou, Z.W.; Pan, S.T.; He, Z.X.; Zhang, X.; Qiu, J.X.; Duan, W.; Yang, T.; Zhou, S.F. Graphene quantum dots induce apoptosis, autophagy, and inflammatory response via p38 mitogen-activated protein kinase and nuclear factor- $\mathrm{kB}$ mediated signaling pathways in activated THP-1 macrophages. Toxicology 2015, 327, 62-76. [CrossRef] [PubMed]

22. Radogna, F.; Cerella, C.; Gaigneaux, A.; Christov, C.; Dicato, M.; Diederich, M. Cell type-dependent ROS and mitophagy response leads to apoptosis or necroptosis in neuroblastoma. Oncogene 2015, 35, 1-15. [CrossRef] [PubMed]

23. Tsukahara, T.; Matsuda, Y.; Haniu, H. The role of autophagy as a mechanism of toxicity induced by multi-walled carbon nanotubes in human lung cells. Int. J. Mol. Sci. 2014, 16, 40-48. [CrossRef] [PubMed]

24. Wan, B.; Wang, Z.X.; Lv, Q.Y.; Dong, P.X.; Zhao, L.X.; Yang, Y.; Guo, L.H. Single-walled carbon nanotubes and graphene oxides induce autophagosome accumulation and lysosome impairment in primarily cultured murine peritoneal macrophages. Toxicol. Lett. 2013, 221, 118-127. [CrossRef] [PubMed] 
25. Qiao, A.; Wang, K.; Yuan, Y.; Guan, Y.; Ren, X.; Li, L.; Chen, X.; Li, F.; Chen, A.F.; Zhou, J.; et al. Sirt3-mediated mitophagy protects tumor cells against apoptosis under hypoxia. Oncotarget 2016. [CrossRef] [PubMed]

26. Daido, S.; Kanzawa, T.; Yamamoto, A.; Takeuchi, H.; Kondo, Y.; Kondo, S. Pivotal role of the cell death factor BNIP3 in ceramide-induced autophagic cell death in malignant glioma cells. Cancer Res. 2004, 64, 4286-4293. [CrossRef] [PubMed]

27. Mc Neil, P.L. Repairing a torn cell surface: Make way, lysosomes to the rescue. J. Cell Sci. 2002, 115, 873-879.

28. Bellot, G.; Garcia-Medina, R.; Gounon, P.; Chiche, J.; Roux, D.; Pouyssegur, J.; Mazure, N.M. Hypoxia-induced autophagy is mediated through hypoxia-inducible factor induction of BNIP3 and BNIP3L via their BH3 domains. Mol. Cell. Biol. 2009, 29, 2570-2581. [CrossRef] [PubMed]

29. Chinnadurai, G.; Vijayalingam, S.; Gibson, S.B. BNIP3 subfamily BH3-only protein: Mitochondrial stress sensors in normal and pathological functions. Oncogene 2007, 27, S114-S127. [CrossRef] [PubMed]

30. Li, Y.; Wang, Y.; Kim, E.; Beemiller, P.; Wang, C.Y.; Swanson, J.; You, M.; Guan, K.L. BNIP3 mediates the hypoxia-induced inhibition on mammalin target of rapamycin by interacting with Rheb. J. Biol. Chem. 2007, 282, 35803-35813. [CrossRef] [PubMed]

31. Friedhuber, A.M.; Chandolu, V.; Manchun, S.; Donkor, O.; Sriamornsak, P.; Dass, C.R. Nucleotropic doxorubicin nanoparticles decrease cancer cell viability, destroy mitochondria, induce autophagy and enhance tumor necrosis. J. Pharm. Pharmacol. 2014, 67, 68-77. [CrossRef] [PubMed]

32. Chng, E.L.; Chua, C.K.; Pumera, M. Graphene oxide nanoribbons exhibit significantly greater toxicity than graphene oxide nanoplatelets. Nanoscale 2014, 6, 10792-10797. [CrossRef] [PubMed]

33. Cataldo, F.; Compagnini, G.; Patanè, G.; Ursini, O.; Angelini, G.; Ribic, P.R.; Margaritondo, G.; Cricenti, A.; Palleschi, G.; Valentini, F. Graphene nanoribbons produced by the oxidative unzipping of single-wall carbon nanotubes. Carbon 2010, 48, 2596-2602. [CrossRef]

34. Valentini, F.; Roscioli, D.; Carbone, M.; Conte, V.; Floris, B.; Palleschi, G.; Flammini, R.; Bauer, E.M.; Nasillo, G.; Caponetti, E. Oxidized graphene in ionic liquids for assembling chemically modified electrodes: A structural and electrochemical characterization study. Anal. Chem. 2012, 84, 5823-5831. [CrossRef] [PubMed]

35. Mari, E.; Zicari, A.; Fico, F.; Massimi, I.; Lolli, M.; Mardente, S. Action of HMGB1 on miR-221/222 cluster in neuroblastoma cell lines. Oncol. Lett. 2016, 12, 2133-2138. [CrossRef] [PubMed]

36. Mardente, S.; Zicari, A.; Consorti, F.; Mari, E.; di Vito, M.; Leopizzi, M.; Della Rocca, C.; Antonaci, A. Cross-talk between NO and HMGB1 in lymphocytic thyroiditis and papillary thyroid cancer. Oncol. Rep. 2010, 24, 1455-1461. [CrossRef] [PubMed]

37. Robinson, J.P. Oxidative metabolism. Curr. Protoc. Cytom. 2001. [CrossRef]

38. Martire, S.; Fuso, A.; Rotili, D.; Tempera, I.; Giordano, C.; De Zottis, I.; Muzi, A.; Vernole, P.; Graziani, G.; Lococo, E.; et al. PARP-1 modulates amyloid beta peptide-induced neuronal damage. PLoS ONE 2013, 8, e72169. [CrossRef] [PubMed]

39. Cossarizza, A.; Baccarani-Contri, M.; Kalashnikova, G.; Franceschi, C. A new method for the cytofluorimetric analysis of mitochondrial membrane potential using the J-aggregate forming lipophilic cation 5,5',6,6'tetrachloro1,1',3,3'tetraethylbenzimidazolylcarbocyanine iodide (JC-1). Biochem. Biophys. Res. Commun. 1993, 197, 40-45. [CrossRef] [PubMed]

(C) 2016 by the authors; licensee MDPI, Basel, Switzerland. This article is an open access article distributed under the terms and conditions of the Creative Commons Attribution (CC-BY) license (http://creativecommons.org/licenses/by/4.0/). 